\title{
Effects of Sub-Minimum Inhibitory Concentrations of Silver Nanoparticles on Some Virulence Factors of Staphylococcus aureus
}

\author{
Azizollah Ebrahimi (PhD) \\ Department of Pathobiology, School of \\ Veterinary Science, Shahrekord \\ University, Shahrekord, Iran \\ Younes Daryalal (DVM) \\ Department of Pathobiology, \\ Veterinary College, Shahrekord \\ University, Shahrekord, Iran \\ Mohamadreza Mahzounieh (PhD) \\ Department of Pathobiology, School of \\ Veterinary Science, Shahrekord \\ University, Shahrekord, Iran \\ Sharareh Lotfalian (MSc) \\ Department of Pathobiology, School of \\ Veterinary Science, Shahrekord \\ University, Shahrekord, Iran \\ Corresponding author: Azizollah \\ Ebrahimi \\ Tel: +989133197980 \\ E-mail: A_kahrizsangi@yahoo.com \\ Address: Department of Pathobiology, \\ School of Veterinary Science, \\ Shahrekord University, Shahrekord, \\ Iran \\ Received : 02 Dec 2017 \\ Revised: 01 Apr 2018 \\ Accepted: 15 Apr 2018 \\ Azizollah Ebrahimi 0000-0002-8846-9991
}

\begin{abstract}
Background and 0bjectives: Silver nanoparticles (AgNPs) have physical and surface properties that could threaten human and environmental health. AgNPs are classified as 'very toxic' to eukaryotic organisms and are less toxic to bacteria. The aim of the present study was to study the effects of different sub-minimum inhibitory concentrations (MICs) of AgNPs on some virulence factors of Staphylococcus aureus as a pathogenic bacterial model.

Methods: Tube double serial dilution method was used to determine NIC of AgNPs against standard strain and ten field isolates of $S$. aureus. Tube cultures of isolates in LB broth were supplemented with different concentrations of AgNPs and were incubated at 37 ${ }^{\circ} \mathrm{C}$ with constant shaking under aerobic conditions. Samples from each tube were streaked on blood agar plates and assay for hemolysins, coagulase and DNase production were performed.
\end{abstract}

Results: The VIC of AgNPs against all examined isolates was determined as $50 \mu \mathrm{g} / \mathrm{mL}$. The results showed that $1 / 2,1 / 4$ and $1 / 8$ MIC of AgNPs had no negative effect on DNase and coagulase production but inhibited alpha- and beta-hemolysin production in most isolates (64-91\%). In addition, production of delta-hemolysin was inhibited by $1 / 2 \mathrm{MIC}$ of AgNPs.

Conclusion: The effects of sub-VIC of AgNPs on bacterial growth appear at 4-8 hours post-exposure and then the bacteria follow a normal growth trend. This toxic effect may affect ecosystems species.

Keywords: Silver particles, Minimum inhibitory concentration, Virulence factors, Staphylococcus aureus. 


\section{INTRODUCTION}

Silver ions are usually not available in concentrations high enough to pose a risk to human health and the environment, but silver nanoparticles (AgNPs) have physical and surface properties that could threaten human and environmental health (1). Indeed, buildup of AgNPs in the environment can act as a reservoir of toxic silver ions in the ecosystems. A recent study analyzed effects of $\mathrm{AgNO}_{3}$ and AgNPs on the composition and metatranscriptome of a natural community of aquatic protists and reported that a day exposure to concentration of $10 \mu \mathrm{g} / \mathrm{L} \mathrm{AgNO}_{3}$ limited the growth of flagellates and dinoflagellates compared to unexposed controls. On the other hand, exposure to AgNPs resulted in less profound effects compared to ionic silver (2). Another study on different NPs including AgNPs showed that crustaceans, algae and fish are the most sensitive, and stated that AgNPs are 'very toxic' to aquatic organisms and less toxic to bacteria compared to aquatic organisms (3). Based on current reports, AgNPs can cause bacterial toxicity through membrane proteins and oxidative damage but do not cause bacterial DNA damage (3). Staphylococci are pyogenic bacteria associated with abscess formation and suppuration. Pathogenic staphylococci produce a 'battery' of toxins including various enzymes such as DNase, coagulase and hemolysins $(\alpha, \beta, \partial)$, which are considered indices of pathogenicity (4).

The antibacterial activity of AgNPs has been well-studied, while the effect of these particles at sub-minimum inhibitory concentrations (MICs) remains unclarified. Therefore, the aim of the present study was to study the effects of sub-MIC of AgNPs on some virulence factors of Staphylococcus aureus as a pathogenic bacterial model.

\section{MATERIAL AND METHODS}

Ten field isolates of $S$. aureus from human skin wound infections in our earlier work (5) and a standard strain of S. aureus (RTCC 1907) were collected from bacterial collection of microbiology laboratory at School of Veterinary Medicine, Shahrekord University, Iran. Primary characterization of isolates was based on Gram staining as well as morphological and cultural characteristics. Colonies were tested with slide coagulase (using rabbit plasma), catalase and DNase tests. Biochemical examinations were performed according to methods described by Murray et al. (6). The hemolytic activity was evaluated by plating the strains on $5 \%$ bovine blood agar (Merck, Germany) for alpha- and beta-hemolysin production. Presence of complete lytic zone (transparent) with blurred edges and incomplete (non-transparent) lytic zone (that became complete with sharp edges after overnight incubation at $4{ }^{\circ} \mathrm{C}$ ) confirmed production of alpha-hemolysin and betahemolysin, respectively (6). Production of delta-hemolysin was determined by the synergistic hemolysis method described by Hebert and Hancock (7). Strains found as positive for DNase, coagulase and $\alpha, \beta, \partial$ hemolysins production were selected for further testing. Colloidal AgNPs with particle size ranging from 10 to $20 \mathrm{~nm}$ (Sigma, CAS Number 7440-22-4) were purchased from Kian Eksir Co., Iran. A dilution of $100 \mu \mathrm{g} / \mathrm{mL}$ AgNPs was prepared from the stock solution $(1000 \mu \mathrm{g} / \mathrm{mL})$ in Muller Hinton broth $(\mathrm{MHb}$, Merck, Germany) after sonication. MHb was used for all antibacterial assays. Tube double serial dilution method was used to determine MIC of AgNPs against S. aureus, according to the guidelines of the Clinical and Laboratory Standards Institute (8). The bacterial cultures in tryptic soy broth (TSB, Merck, Germany) were incubated aerobically at $37{ }^{\circ} \mathrm{C}$ for $18-24$ hours. Turbidity of the cultures was adjusted to 0.5 McFarland $\left(1.5 \times 10^{8} \mathrm{CFU} / \mathrm{ml}\right)$ and then diluted in saline solution to obtain an inoculum of $5 \times 10^{6} \mathrm{CFU} /$ tube. Positive and negative controls were also prepared. The inoculated tubes were incubated aerobically at $37{ }^{\circ} \mathrm{C}$ with shaking for about 18 hours. The lowest concentration that inhibited visible growth of bacteria was defined as MIC. All experiments were performed in triplicate. To analyze the effect of sub-MIC of AgNPs on the growth of $S$. aureus isolates, overnight cultures of the standard strain was inoculated into tubes containing Lauria Bertani broth (LB, Biomark, India) supplemented with $1 / 2$ MIC of AgNPs arranged as $\mathrm{MHb}$ and inoculated bacteria, $\mathrm{MHb}+1 / 2$ MIC AgNPs + inoculated bacteria, and water $+1 / 2$ MIC AgNPs. The tubes were incubated with shaking at $37{ }^{\circ} \mathrm{C}$, and $\mathrm{OD}_{600 \mathrm{~nm}}$ was recorded at 2-hour intervals for up to 12 hours. The tubes supplemented with $1 / 2$ MIC $(25 \mu \mathrm{g} / \mathrm{mL}), 1 / 4 \mathrm{MIC}(12.5 \mu \mathrm{g} / \mathrm{mL})$ and $1 / 8$ MIC $(6.2 \mu \mathrm{g} / \mathrm{mL})$ of AgNPs were grown at 37 
${ }^{\circ} \mathrm{C}$ with constant shaking under aerobic conditions.

After 24 hours, samples from each tube were streaked on blood agar plates and the plates were incubated at $37^{\circ} \mathrm{C}$ for 24 hours. Finally, assays for hemolysins, coagulase and DNase production were performed as described previously.

\section{RESULTS}

Our examinations showed that $1 / 2$ MIC of AgNPs can alter the growth rate of the standard strain of $S$. aureus when compared to the controls (Figure 1).

The MIC of AgNPs against all $S$. aureus isolates was determined as $50 \mu \mathrm{g} / \mathrm{mL}$. The results showed that AgNPs at $1 / 2(25 \mu \mathrm{g} / \mathrm{mL})$, $1 / 4(12.5 \mu \mathrm{g} / \mathrm{mL})$ and $1 / 8(6.2 \mu \mathrm{g} / \mathrm{mL})$ MICs had no negative effect on DNase and coagulase production.

As shown in table 1, AgNPs at sub-MICs of $1 / 2$ to $1 / 8$ prevented production of alpha- and beta-hemolysins in most isolates (64-91\%). However, inhibition of delta-hemolysin production was noted only at $1 / 2$ MIC of AgNPs.

\section{Figure 1- Growth curves of $S$. aureus RTCC 1907 cultured in MHb with and without 1/2 MIC of AgNPs}

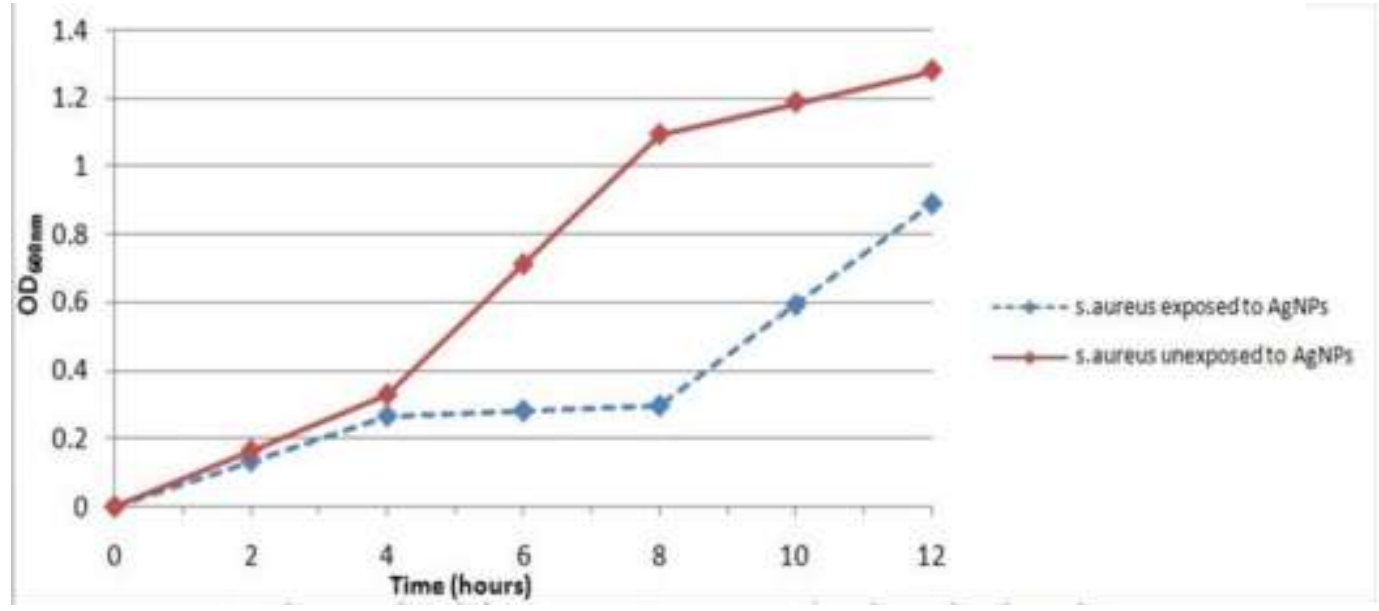

Table 1- The effect of different MICs of AgNPs on hemolvsins production by $\boldsymbol{S}$. aureus isolates

\begin{tabular}{|c|c|c|c|c|c|c|c|c|c|c|}
\hline \multicolumn{2}{|l|}{ Hemolysin } & \multicolumn{2}{|r|}{$\alpha$} & \multicolumn{4}{|c|}{$\boldsymbol{\beta}$} & \multicolumn{3}{|c|}{$\partial$} \\
\hline \multirow[t]{2}{*}{ MIC } & \multirow[t]{2}{*}{$1 / 2$} & \multirow[t]{2}{*}{$1 / 4$} & \multirow[t]{2}{*}{$1 / 8$} & \multirow{2}{*}{$\begin{array}{r}1 / 2 \\
\text { Bacteria }\end{array}$} & \multicolumn{2}{|c|}{$1 / 4$} & $1 / 8$ & \multirow[t]{2}{*}{$1 / 2$} & \multirow[t]{2}{*}{$1 / 4$} & \multirow[t]{2}{*}{$1 / 8$} \\
\hline & & & & & & & & & & \\
\hline Standard & + & + & + & & + & + & + & + & - & - \\
\hline Isolate 1 & + & - & - & & - & - & - & + & - & - \\
\hline Isolate 2 & + & + & + & & - & - & - & - & - & - \\
\hline Isolate 3 & + & + & + & & + & + & + & + & - & - \\
\hline Isolate 4 & + & - & - & & + & - & - & + & - & - \\
\hline Isolate 5 & + & + & + & & + & + & + & - & - & - \\
\hline Isolate 6 & - & - & - & & + & + & + & + & - & - \\
\hline Isolate 7 & + & + & + & & - & - & - & - & - & - \\
\hline Isolate 8 & + & + & + & & + & + & + & + & - & - \\
\hline Isolate 9 & + & + & + & & + & + & + & + & - & - \\
\hline Isolate 10 & + & + & + & & + & + & + & + & - & - \\
\hline$\%$ of inhibition & 91 & 73 & 73 & & 73 & 64 & 64 & 73 & $\mathbf{0}$ & $\mathbf{0}$ \\
\hline
\end{tabular}

+: No hemolysin produced, - : Hemolysin production continued 


\section{DISCUSSION}

Exposure to 1/2 MIC of AgNPs can alter the growth of the standard strain of $S$. aureus (Figure 1). It seems that the growth rate was not affected for up to 4 hours after incubation but was decreased after 4-8 hours of AgNPs exposure. This may indicate that the toxic effects of AgNPs appear at 4-8 hours post-exposure and then a repairing mechanism might occur that revert these effects, enabling $S$. aureus to follow a normal growth trend.

Sub-MICs of AgNPs caused a significant decrease in hemolysin production by $S$. aureus isolates. It is known that NPs are less toxic to bacteria than to other organisms [3], so this toxic effect can be more severe in humans and other species.

A previous study showed that sub-MICs of some antibiotics are able to alter expression of the $\alpha$-hemolysin gene in methicillin-sensitive and methicillin-resistant S. aureus (9).

AgNPs can damage the DNA and chromosomes and may induce mutagenicity (10), which could be also responsible for decreasing production of beta- and deltahemolysins following exposure to AgNPs. According to Hwang et al., the antibacterial activity of AgNPs is due to the combination of silver ions and NPs (11). Effect of low, noncytotoxic concentration of $\operatorname{AgNPs}(5 \mu \mathrm{g} / \mathrm{mL})$ on human cytokines production was previously demonstrated (12). Another study also revealed that AgNPs are amongst the most cytotoxic NPs when exposed to macrophage and epithelial cell lines (13). AgNPs are incorporated in products such as water filters, cosmetics, antimicrobials, etc., which increase the risk of its leakage to different environments (14).

In our study, sub-MICs of AgNPs had no significant impact on coagulase and DNase production in the examined isolates. Amini et al. also reported that exposure of $S$. aureus to different sub-MICs of penicillin, vancomycin

\section{REFERENCES}

1.Park S, Lee YK, Jung M, Kim KH, Chung N, Ahn EK, et al. Cellular toxicity of various inhalable metal nanoparticles on human alveolar epithelial cells. Inhalation Toxicology. 2007;19(sup1): 59-65. DOI: $10.1080 / 08958370701493282$.

2. Boenigk J, Beisser D, Zimmermann S, Bock C, Jakobi $\mathrm{J}$, Grabner $\mathrm{D}$, et al. Effects of silver nitrate and silver nanoparticles on a planktonic community: general trends after short-term exposure. PloS one. 2014; 9(4):e95340. DOI: 10.1371/journal.pone.0095340. and ceftazidime does not affect coagulase and DNase production (15). Moreover, Dos et al. revealed that sub-MICs of some antibiotics have little effects on coagulase production in $S$. aureus but inhibit hemolysins production (16). In a study by Gambino et al. on soil bacterial communities (17), low concentrations of AgNPs eliminated Azotobacter vinelandii isolates and affected cellular processes in Bacillus subtilis isolates. Yang et al. (18) indicated that exposure to sub-lethal concentrations of AgNPs positively affected biofilm production, quorum sensing, lipopolysaccharide biosynthesis and antibiotic resistance in Pseudomonas aeruginosa. However, we could not find any study on the effects of sub-MICs of AgNPs on production of excretory proteins in $S$. aureus. Beside the ecological side effects of sub-MICs of AgNPs, their effects from the therapeutic perspective should also be taken into account. Considering the antimicrobial potential of AgNPs, diluted concentrations of these NPs could be used as antibacterial agents against $S$. aureus (4).

\section{CONCLUSION}

Our results show that AgNPs exhibit potent anti-hemolytic activities with no negative effect on DNase and coagulase production in $S$. aureus isolates. Further studies on the effect of sub-MICs of these NPs on other bacteria could provide more insight on the therapeutic potential of AgNPs.

\section{ACKNOWLEDGMENTS}

The authors appreciate all those who contributed to the study. This study was derived from a DVM thesis project performed by Dr. Younes Daryalal.

\section{CONFLICT OF INTEREST} interest.

The authors declare no conflict of

3. Bondarenko O, Juganson K, Ivask A, Kasemets $\mathrm{K}$, Mortimer M, Kahru A. Toxicity of $\mathrm{Ag}, \mathrm{CuO}$ and $\mathrm{ZnO}$ nanoparticles to selected environmentally relevant test organisms and mammalian cells in vitro: a critical review. Archives of Toxicology. 2013; 87(7): 1181-200. DOI: $10.1007 / \mathrm{s} 00204-013-1079-4$.

4. Quinn PJ, Markey BK, Leonard FC, FitzPatrick ES, Fanning S, Hartigan P. Veterinary microbiology and microbial disease. John Wiley \& Sons. 2011; 539- 560. 
5.Ebrahimi A, Ghasemi M, Ghasemi B. Some virulence factors of Staphylococci isolated from wound and skin infections in Shahrekord, IR Iran. Jundishapur Journal of Microbiology. 2014;7(4). e9225. DOI: $10.5812 /$ jjm.9225.

6.Murray PR, Baron EJ, Jorgensen J, Landry M, Pfaller M. Manual of clinical microbiology. $9^{\text {th }}$ ed. 2006; 11267.

7.Hebert G, Hancock GA. Synergistic hemolysis exhibited by species of staphylococci. Journal of clinical microbiology. 1985; 22(3): 409-15.

8. Wayne P. Clinical and Laboratory Standarts Institute: Methods for Dilution Antimicrobial Susceptibility Tests for Bacteria that grow aerobically. Approved Standart M7-A7, CLSI, USA; 2006. DOI: 10.1007/s13273-0100018-1.

9. Ohlsen K, Ziebuhr W, Koller K-P, Hell W, Wichelhaus TA, Hacker J. Effects of subinhibitory concentrations of antibiotics on alpha-toxin (hla) gene expression of methicillin-sensitive and methicillinresistant Staphylococcus aureus isolates. Antimicrobial agents and chemotherapy. 1998; 42(11): 2817-23.

10. Nallanthighal S, Chan C, Bharali DJ, Mousa SA, Vásquez E, Reliene R. Particle coatings but not silver ions mediate genotoxicity of ingested silver nanoparticles in a mouse model. NanoImpact. 2017; 5: 92-100. DOI: 10.1016/j.impact.2017.01.003.

11. Hwang ET, Lee JH, Chae YJ, Kim YS, Kim BC, Sang BI, et al. Analysis of the Toxic Mode of Action of Silver Nanoparticles Using Stress-Specific Bioluminescent Bacteria. Small. 2008; 4(6): 746-50. DOI:10.1002/smll.200700954.
12. Shin S-H, Ye M-K, Kim H-S, Kang H-S. The effects of nano-silver on the proliferation and cytokine expression by peripheral blood mononuclear cells. International journal of immunopharmacology. 2007; 7(13): 1813-8. DOI: 10.1016/j.intimp.2007.08.025.

13. Soto K, Garza K, Murr L. Cytotoxic effects of aggregated nanomaterials. Acta Biomaterialia. 2007; 3(3): 351-8. DOI:10.1016/j.actbio.2006.11.004.

14. Wijnhoven SW, Peijnenburg WJ, Herberts CA, Hagens WI, Oomen AG, Heugens EH, et al. Nanosilver-a review of available data and knowledge gaps in human and environmental risk assessment. Nanotoxicology. 2009; 3(2): 109-38. DOI: $10.1080 / 17435390902725914$.

15. Amini B, Baghchesaraie H, Haji Ojagh Faghihi M. Effect of different sub MIC concentrations of penicillin, vancomycin and ceftazidime on morphology and some biochemical properties of Staphylococcus aureus and Pseudomonas aeruginosa isolates. Iranian Journal of Microbiology. 2009; 1(1): 43-7.

16. Doss S, Tillotson G, Amyes S. Effect of subinhibitory concentrations of antibiotics on the virulence of Staphylococcus aureus. Journal of applied bacteriology . 1993; 75(2):123-8.

17. Gambino M, Marzano V, Villa F, Vitali A, Vannini C, Landini P, Cappitelli F. Effects of sublethal doses of silver nanoparticles on Bacillus subtilis planktonic and sessile cells. Journal of applied microbiology. 2015; 118(5): 1103-15. DOI: 10.1111/jam.12779.

18. Yang Y, Alvarez PJ. Sublethal concentrations of silver nanoparticles stimulate biofilm development. Environmental Science and Technology Letters. 2015; 2(8): 221-6. DOI: 10.1021/acs.estlett.5b00159. 